\title{
Nitrogen-doped porous carbons from bipyridine- based metal-organic frameworks: Electrocatalysis for oxygen reduction reaction and Pt-catalyst support for methanol electrooxidation
}

\author{
Dandan Zhu ${ }^{a, b}$, Liangjun Li ${ }^{a, c}$, Jinjun Cai ${ }^{a, b}$, Min Jiang ${ }^{a, *}$, Jingbo Qi ${ }^{a, b}$, \\ Xuebo Zhao ${ }^{a, c, *}$ \\ a Applied Energy Technology Center, Qingdao Institute of Bioenergy and Bioprocess Technology, Chinese Academy of Sciences, \\ Qingdao 266101, PR China \\ ${ }^{\mathrm{b}}$ University of Chinese Academy of Sciences, Beijing 100049, PR China \\ c Institute of Unconventional Hydrocarbon and New Energy Sources, China University of Petroleum (East China), Qingdao 266580, PR China
}

\section{A R T I C L E I N F O}

Article history:

Received 5 May 2014

Accepted 7 August 2014

Available online 14 August 2014

\begin{abstract}
A B S T R A C T
A novel pyridine-containing metal-organic framework (MOF), [Zn(bpdc)DMA]·DMF, was first constructed by solvothermal reaction of 2,2'-bipyridine-5,5'-dicarboxylate (bpdc) with zinc nitrate, and then it was converted to nitrogen-doped porous carbons (NPCs) by direct carbonization. The as-prepared porous carbon (NPC800) was characterized by scanning electron microscopy (SEM), X-ray powder diffraction (XRD), $\mathrm{N}_{2}$ sorption isotherms, and Xray photoelectron spectroscopy. NPC800 was modified onto glassy carbon electrode surface for investigating its electrochemical applications. Cyclic voltammetry (CV) and linear sweep voltammetry were performed to evaluate the electrocatalytic activity of NPC800 for oxygen reduction reaction (ORR) in alkaline solution. NPC800 exhibited better ORR activity than commercial Pt/C. Pt-catalyst supported on NPCs (Pt/NPC800) was prepared by means of electrodeposition and characterized by SEM, Energy dispersive spectrometry and XRD. The electrocatalytic activity and stability of Pt/NPC800 for methanol oxidation reaction (MOR) were estimated in acidic methanol solution by $\mathrm{CV}$ and chronoamperometric curves, respectively. Pt/NPC800 showed catalytic role for MOR, and also had better stability than Pt-catalyst supported on commercial Vulcan XC-72.
\end{abstract}

(c) 2014 Elsevier Ltd. All rights reserved.

\section{Introduction}

Porous carbon-based materials have been widely investigated in different research fields including gas storage [1,2] and separation $[3,4]$, electrocatalyst $[5,6]$ and capacitor $[7,8]$. There are extensive approaches to obtain porous carbons such as template method [9], direct carbonization [10], sol-gel synthesis [7], physical and chemical activation [11], in which direct carbonization of precursor is a simple and effective method without any other additives [10]. Various kinds of precursors

\footnotetext{
* Corresponding authors: Fax: +86 53280662728 (M. Jiang). Address: Applied Energy Technology Center, Qingdao Institute of Bioenergy and Bioprocess Technology, Chinese Academy of Sciences, Qingdao 266101, PR China. Fax: +86 53280662728 (X. Zhao).

E-mail addresses: jiangmin@qibebt.ac.cn (M. Jiang), zhaoxb@qibebt.ac.cn (X. Zhao). 
can be applied to prepare porous carbons [12-15] with specific characteristics. Therefore, it is of great importance to explore a suitable precursor for the synthesis of porous carbons with high surface areas and pore volumes, in different fields, especially for the electrochemical applications.

Metal-organic frameworks (MOFs) are a class of crystalline porous materials with high surface area, large pore volume, and chemistry tenability. They have also been utilized as templates or precursors to synthesize porous carbons. Liu et al. [12] firstly utilized MOF-5 as a template to prepare porous carbon with a surface area of $2827 \mathrm{~m}^{2} \mathrm{~g}^{-1}$, displaying the hydrogen capacity of up to $2.6 \mathrm{wt} \%$ at 1 bar and $77 \mathrm{~K}$, and excellent electrochemical performance. Subsequently, several research groups [16-25] employed other MOFs to prepare porous carbons for various applications. Radhakrishnan et al. [18] reported the carbonization of Al-based porous coordination polymer (Al-PCP) with furfural alcohol as carbon source for the preparation of microporous carbon fibers, displaying the potential use in catalysis. Chaikittisilp et al. [19] used a zeolitic imidazolate framework (ZIF-8) to synthesize porous carbons with high electrochemical capacitances through direct carbonization. Moreover, Yang et al. [20] employed IRMOF-1, 3, and 8 to prepare hierarchically porous carbons and investigated their hydrogen storage performance. Based on the reported works, MOFs can not only serve as porous template $[16,18,25-27]$ to prepare porous carbons in the presence of other carbon sources, such as furfural alcohol and glucose, they can also act as self-sacrificed precursor (including intrinsic porous and nonporous MOFs [28,29]) through direct carbonization without addition of other carbon sources. Therefore, the design and synthesis of MOFs is very crucial for the preparation of porous carbons, especially with some heteroatoms doping. Oxygen reduction reaction (ORR) is the cathodic reaction of fuel cells. Carbon materials doped with nitrogen, especially with pyridinic $\mathrm{N}$, can improve ORR catalytic activity [30]. In view of the rich $\mathrm{N}$ atom in imidazolate ligands of ZIF, Ma et al. [17] applied Co-ZIF for the first time to prepare nitrogen-doped porous carbons (NPCs) with Co- $\mathrm{N}_{4}$ catalytic site for oxygen reduction; afterwards, they also used Fe-ZIF for the same purpose [21]. Recently, Zhang et al. [25] employed ZIF-7 to synthesize NPCs and the metalfree NPCs showed superior electrocatalytic performance for ORR. They proposed that not only ZIF, but also other nitrogen-containing MOFs can be regarded as precursor and nitrogen source to prepare NPCs. To the best of our knowledge, there is no report on the preparation of NPCs from MOF precursor containing pyridine-based ligands, which may be helpful to enhance the functionality of nitrogen in porous carbons for ORR. In addition, porous carbons can also serve as catalyst support for various catalytic reactions such as methanol electrooxidation [31] by use of its porosity. Methanol oxidation reaction (MOR) is the anodic reaction of direct methanol fuel cell. The development of well-known Pt/C catalysts for MOR faces the challenges of their insufficient performance and poor long-term stability [32]. Su et al. [33] pointed out that the presence of $\mathrm{N}$ species on the carbon support surface could lead to high dispersion of Pt nanoparticles and the stronger Pt-support interaction, which resulted in the enhanced catalytic activity and durability toward ORR and MOR [34]. It is expected that Pt-based catalyst supported on NPCs derived from MOFs will exhibit better catalytic durability.

For the above purpose, we designed and synthesized a novel pyridine-containing MOF, [Zn(bpdc)DMA].DMF (bpdc $=2,2^{\prime}-$ bipyridine-5,5'-dicarboxylate, $\quad \mathrm{DMA}=\mathrm{N}, \mathrm{N}^{\prime}$-dimethylacetamide, $\quad \mathrm{DMF}=\mathrm{N}, \mathrm{N}^{\prime}$-dimethylformamide), by solvothermal reaction. This is the first example that the pyridine groups in the organic linker of a MOF can serve as a nitrogen atom source for NPC materials. The structure of this MOF was characterized by single-crystal X-ray diffraction. We attempted to prepare NPCs (NPC800) from the as-synthesized [Zn(bpdc)DMA]·DMF by direct carbonization at $800^{\circ} \mathrm{C}$, and characterized the final product by scanning electron microscopy (SEM), X-ray powder diffraction (XRD), $\mathrm{N}_{2}$ sorption isotherms and X-ray photoelectron spectroscopy (XPS). Pt-based catalyst supported on NPCs (Pt/NPC800) was prepared by means of electrodeposition and characterized by SEM, Energy dispersive spectrometry (EDS) and XRD. The catalytic activity of NPC800 for ORR and Pt/ NPC800 for MOR were further investigated by electrochemical methods.

\section{Experimental}

\subsection{Materials}

Chloroplatinic acid hexahydrate $\left(\mathrm{H}_{2} \mathrm{PtCl}_{6} \cdot 6 \mathrm{H}_{2} \mathrm{O}, 99.9 \%\right)$ and commercial $10 \mathrm{wt} \% \mathrm{Pt} / \mathrm{C}$ were purchased from Aladdin Industrial Corporation. $5 \mathrm{wt} \%$ Nafion solution was obtained from Aldrich. Vulcan XC-72 was purchased from Cabot Corp. Ultrapure (99.999\%) nitrogen and oxygen was purchased from Qingdao Heli gas Co., Ltd. All other reagents were obtained from Sinopharm Chemical Reagent Co., Ltd and used as received without further purification. Water was obtained from a Millipore system with a resistivity larger than $18 \mathrm{M} \Omega \mathrm{cm}$.

\subsection{Synthesis of [Zn(bpdc)DMA]·DMF}

The ligand bpdc was prepared according to the previous procedure reported by our group [35,36]. Subsequently, $\mathrm{Zn}\left(\mathrm{NO}_{3}\right)_{2}$ $\cdot 6 \mathrm{H}_{2} \mathrm{O}(238 \mathrm{mg}, 0.8 \mathrm{mmol})$, bpdc ligand $(97.6 \mathrm{mg}, 0.4 \mathrm{mmol}$ ) and DMA/DMF $(15 \mathrm{~mL} / 8 \mathrm{~mL})$ were mixed in a Teflon-lined autoclave. After the mixture was stirred at room temperature for $30 \mathrm{~min}$, the autoclave was heated at $100^{\circ} \mathrm{C}$ for $72 \mathrm{~h}$ and then cooled to room temperature over $24 \mathrm{~h}$. Pure phase of colorless block crystals were obtained through filtration followed by washing with DMF (name as compound 1). To avoid destruction of crystals by moisture in air, the solvent in assynthesized crystals was washed with $\mathrm{CHCl}_{3}$ and then dried under vacuum. The sample was kept in a bottle filled with $\mathrm{N}_{2}$ atmosphere. The yield was about $80.2 \%$ on the basis of the ligand. The formula of compound 1 was determined as [Zn(bpdc)DMA]·DMF based on single-crystal X-ray analysis, elemental analysis and thermo gravimetric analysis (TGA). Elemental Analysis (\%): Calcd. for $\mathrm{C}_{19} \mathrm{H}_{22} \mathrm{~N}_{4} \mathrm{O}_{6} \mathrm{Zn}$ (467.81): C 48.77, H 4.70, N 11.97; Found: C 49.21, H 4.84, N 12.30. Infrared $\left(\mathrm{KBr}, \mathrm{cm}^{-1}\right.$ ): 3109 (w), 2932 (m), 1626 (vs), 1606 (vs), 1508 (m), 1368 (vs), 1258 (m), 1157 (m), 1123 (w), 1308 (s), 846 (s), 779 (s), $711(\mathrm{~m}), 589(\mathrm{w})$. 
Crystallographic details for compound 1 are summarized in Table S1 (Supporting information). CCDC-994732 (for compound 1) contains the supplementary crystallographic data for this paper. These data can be obtained free of charge from the Cambridge Crystallographic Data Centre via www.ccdc.cam.ac.uk/data_request/cif.

\subsection{Preparation of NPC800}

The precursor compound 1 was directly carbonized at $800^{\circ} \mathrm{C}$ under $\mathrm{N}_{2}$ atmosphere for $3 \mathrm{~h}$ in a vertical tubular furnace at the heating rate of $4{ }^{\circ} \mathrm{C} \mathrm{min}{ }^{-1}$. Then, the obtained carbons were treated with $4 \mathrm{~mol} \mathrm{~L}^{-1} \mathrm{HCl}$ solution for $3 \mathrm{~h}$ at $60^{\circ} \mathrm{C}$ to remove probable inorganic impurities. The resulting product was repeatedly rinsed with deionized water until the filtrate became neutral in $\mathrm{pH}$. The collected product was dried in a convection oven at $120^{\circ} \mathrm{C}$ for $10 \mathrm{~h}$. The as-prepared carbon material was denoted as NPC800.

\subsection{Modification of working electrode}

Prior to use, glassy carbon electrode (GCE) with a diameter of $3 \mathrm{~mm}$ and rotating disk electrode (RDE) with a diameter of $3.2 \mathrm{~mm}$ were polished mechanically with alumina slurry, washed with Milli-Q water and ethanol, and then allowed to dry. To prepare working electrodes, 2 mg NPC800 or commercial $10 \mathrm{wt} \% \mathrm{Pt} / \mathrm{C}$ was dispersed into $1 \mathrm{~mL} 0.15 \mathrm{wt} \%$ Nafion ethanol solution to obtain homogeneous suspension through bath sonication. Then a $5 \mu \mathrm{L}$ of the suspension was drop-casted on GCE or RDE and the modified electrode was dried at room temperature for ORR. In the case of MOR, a certain amount of Pt (21 wt\%) was loaded on NPC800-modified GCE using electrodeposition (amperometric $i-t$ curve) in $0.5 \mathrm{~mol} \mathrm{~L}^{-1} \mathrm{HCl}$ and $5 \mathrm{mmol} \mathrm{L}^{-1} \mathrm{H}_{2} \mathrm{PtCl}_{6}$ solution at $-0.15 \mathrm{~V}$. The obtained electrode was named as Pt/NPC800 GCE and used as working electrode. For comparison, Pt/XC-72 GCE working electrode was prepared using the same procedure with Pt/NPC800 GCE to achieve the same Pt-loading amount and utilized for MOR.

\subsection{Physical characterization}

Single-crystal X-ray diffraction was measured at $195 \mathrm{~K}$ on a Bruker SMART APEX2 CCD area detector equipped with graphite-monochromated Mo-K $\alpha$ radiation $(\lambda=0.71073 \AA)$. TGA was conducted on a NETZSCH STA 449F3 unit at a heating rate of $10 \mathrm{~K} \mathrm{~min}^{-1}$ under nitrogen atmosphere. Elemental analyses for $\mathrm{C}, \mathrm{H}$, and $\mathrm{N}$ were carried out with a German Elementary Vario EL cube instrument. Fourier transform infrared (FT-IR) measurement was performed on a Nicolet 6700 FTIR spectrometer. SEM images were obtained with a Hitachi S-4800 (Japan) scanning electron microscope equipped with EDS at an acceleration voltage of $15 \mathrm{kV}$. XRD patterns were carried out with a Bruker D8 ADVANC800ED X-ray diffractometer using $\mathrm{Cu}-\mathrm{K} \alpha$ radiation $(\lambda=1.5418 \AA)$. The nitrogen sorption experiments were performed at $77 \mathrm{~K}$ on a static volumetric sorption analyzer (ASAP2020, Micrometrics, USA). XPS measurements were recorded on Thermo ESCALAB 250 spectroscopy with a monochromic X-ray source (Al-Ka, $1486.6 \mathrm{eV})$.

\subsection{Electrochemical measurements}

Cyclic voltammetry (CV) and chronoamperometry were performed in a conventional three-electrode cell using a CHI660D (Shanghai Chenhua, China) electrochemical workstation. Linear sweep voltammetry (LSV) was carried out on a RRDE-3A (ALS Co., Ltd) with a RDE and a CHI400A (Shanghai Chenhua, China) electrochemical workstation. For ORR, a platinum wire and saturated calomel electrode (SCE) were used as counter electrode and reference electrode, respectively. The electrochemical measurements were performed in $\mathrm{N}_{2}$ or $\mathrm{O}_{2}$-saturated $0.1 \mathrm{~mol} \mathrm{~L}^{-1} \mathrm{KOH}$ at a scan rate of $20 \mathrm{mV} \mathrm{s}^{-1}$. For MOR, a platinum wire and $\mathrm{Ag} / \mathrm{AgCl}$ (KCl-saturated) were used as counter electrode and reference electrode, respectively. The electrochemical measurements were performed in $\mathrm{N}_{2}$-saturated $0.5 \mathrm{~mol} \mathrm{~L}^{-1} \mathrm{H}_{2} \mathrm{SO}_{4}$ solution containing $0.5 \mathrm{~mol} \mathrm{~L}^{-1}$ methanol at a scan rate of $50 \mathrm{mV} \mathrm{s}^{-1}$. All electrochemical experiments were carried out at room temperature.

\section{Results and discussion}

\subsection{Structural description, XRD and TGA of [Zn(bpdc)DMA]·DMF}

Single-crystal X-ray analysis revealed that compound 1 crystallized in an orthorhombic space group Fdd2 with $a=21.4735$ (11) $\AA, \quad b=41.459$ (3) $\AA, \quad c=9.7163(7) \AA, V=8650.0$ (10) $\AA^{3}$. The asymmetric unit contains one $\mathrm{Zn}(\mathrm{II})$ ion, one bpdc ligand and one coordinated DMA molecular (Fig. S1, Supporting information). The $\mathrm{Zn}$ (II) metal centers were coordinated by two oxygen donor atoms from carboxylates, two nitrogen atoms from 2,2'-bipyridine moieties and one oxygen atom from coordinated DMA molecule, leading to a five-coordinated trigonal pyramid geometry (as shown in Fig. 1a). The carboxylate groups in bpdc linker were connected by two $\mathrm{Zn}$ (II) ions in a monodentate form, while the 2,2'-bipyridine moieties were coordinated to one $\mathrm{Zn}$ (II) ion in a chelated form. Since bpdc contains two donor sites, it can connect three metal centers. However, some hard metal ions such as lanthanide or early transition metals prefer to bind bpdc only via the oxygen atoms in bpdc [35,36]. In contrast, $\mathrm{Zn}$ (II), a borderline Lewis acid, is coordinated by both the $\mathrm{O}$ and $\mathrm{N}$ atoms as shown in some complexes that bpdc act as ligand [37]. Selfassembly of ligands and $\mathrm{Zn}$ (II) ions in such a mode finally gave a three-dimensional network as shown in Fig. 1b. A series of parallel narrow pores $(0.4 \mathrm{~nm} \times 0.6 \mathrm{~nm})$ were formed along $c$ axis upon considering Van der Waals radius. Regarding the ligand bpdc as a T-shape linker and the metal centers as a three connected nodes, the crystalline structure of compound 1 can be simplified into a 3-connected network with the point symbol of $\left\{10^{3}\right\}$ (as shown in Fig. 1c). The topological type is utq which is slightly different from the SiSr2 topology. This network can be viewed as the combination of the smaller rectangular channels and the surrounding larger rectangular channels. The larger channels were composed of two parallel helical chains running in the L-helix fashion, while the smaller channels were composed of one R-helix chains (as shown in Fig. 1d). The assembly of the L-helix and R-helix channels resulted in a three dimensional network with 
(a)

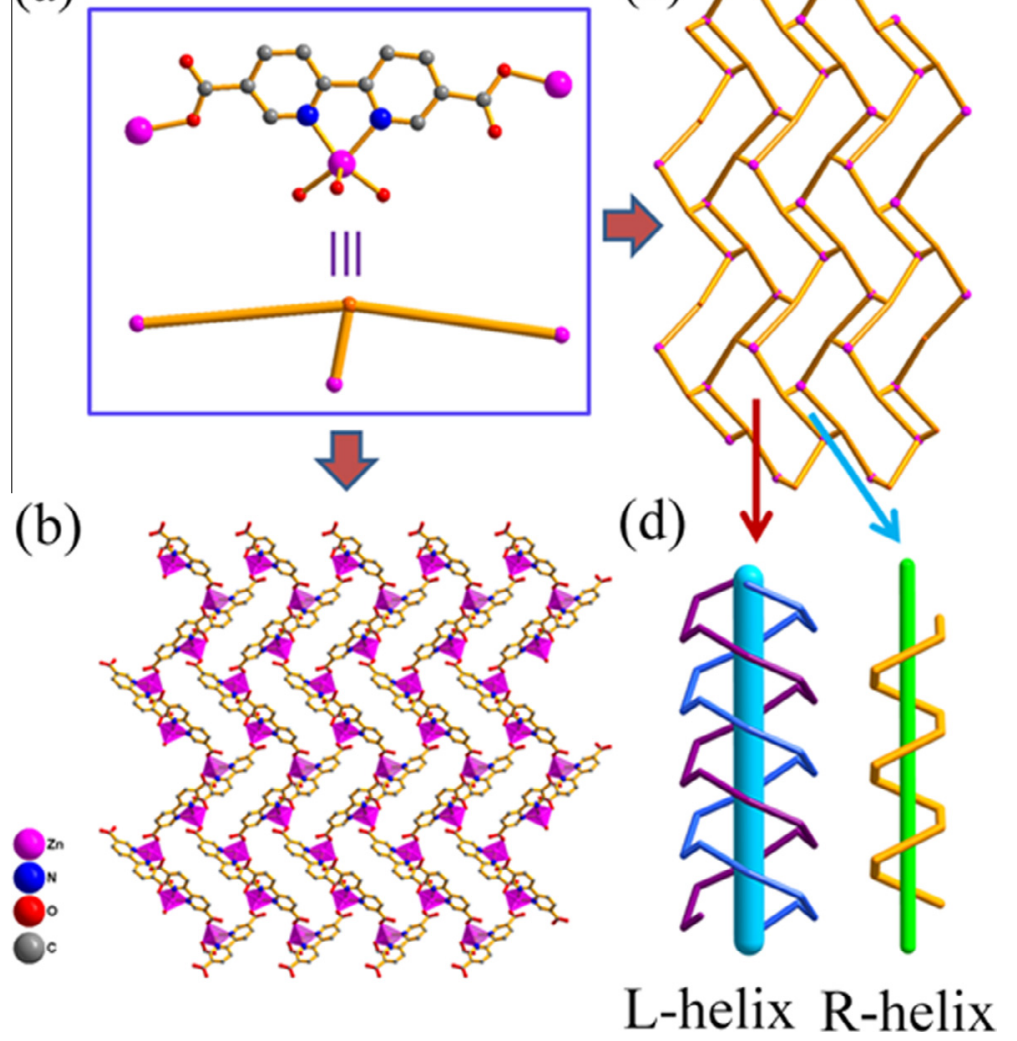

Fig. 1 - The structural feature of compound 1. (a) A simplified unit for the extended network: Zinc ions (pink balls) are represented as nodes, and the half of bpdc (orange sticks) is regarded as a connector linking the nodes. (b) A crystal structure viewed along the crystallographic $c$ axis. (c) A network structure displayed with the nodes and connectors in (a), and (d) the $L$ and $R$ helical chains in the network are running along the $c$ axis. (A color version of this figure can be viewed online.)

one-dimensional channels, which would be helpful for constructing ordered porous carbon materials.

Based on above description, the structure of compound 1 has been understood profoundly. XRD was further performed to confirm the phase purity and crystallinity of compound 1 . Fig. S2 (Supporting information) showed the experimental XRD pattern of compound 1 and the simulated counterpart from the single-crystal structure data. The two patterns are in good agreement with each other, demonstrating that compound 1 is very pure. The SEM image of compound 1 was shown in Fig. S3 (Supporting information), and compound 1 crystallized in an arrow-like shape. TGA measurement of compound 1 was performed under a $\mathrm{N}_{2}$ atmosphere at a heating rate of $10^{\circ} \mathrm{C} \mathrm{min}{ }^{-1}$ in order to evaluate the thermal stability and carbonization temperature of compound 1 (Fig. S4, Supporting information). The weight loss of $34.7 \%$ upon the temperature range from $25^{\circ} \mathrm{C}$ to $225^{\circ} \mathrm{C}$ corresponded to the removal of free and coordinated guest molecules, such as DMF and DMA (calcd. 34.2\%). A plateau was shown in the range of $225-420^{\circ} \mathrm{C}$ on TGA plot, indicating that compound $1 \mathrm{kept}$ stable up to $420^{\circ} \mathrm{C}$. Subsequently, an obvious weight loss of about $16 \%$ happened owing to the decomposition of compound 1 . The gradual decrease of weight above $490^{\circ} \mathrm{C}$ was assigned to the carbonization process of the materials. In this work, compound 1 was carbonized at $800^{\circ} \mathrm{C}$ to prepare porous carbon. For comparison, the parameters of NPCs obtained at $1000^{\circ} \mathrm{C}$ and its electrocatalytic behavior were provided in Supporting information.

\subsection{NPC800 derived from $[\mathrm{Zn}(b p d c) D M A] \cdot D M F$}

\subsubsection{Physical characterization of NPC800}

The structure, porosity and composition of NPC800 were characterized by corresponding techniques. The SEM image of NPC800 was shown in Fig. 2a. It was clearly to see that the structure of NPC800 was irregular and has sharp edges, indicating that compound 1 as self-sacrificed precursor had been broken down and carbonized completely with the conversion of organic linkers to carbons. XRD pattern of NPC800 (Fig. 2b) showed two broad peaks at $2 \theta$ about $23^{\circ}$ and $44^{\circ}$, which were assigned to the (002) and (100) planes of carbon, indicating the low graphitic degrees of this carbon [24]. Considering graphitization in carbon would decrease the surface area and make active sites inaccessible [21], the low graphitization of this carbon is favorable to its catalytic activity.

Because as-synthesized compound 1 possesses narrow pores along $c$ axis, such precursor is favorable for the formation of porous carbon during carbonization. Fig. 2c showed the typical $\mathrm{N}_{2}$ adsorption-desorption curve of NPC800 using the same method with our group reported previously [38]. The rapid increase of the adsorbed volume when $P / P_{0}$ was less than 0.02 showed the presence of large quantities of 

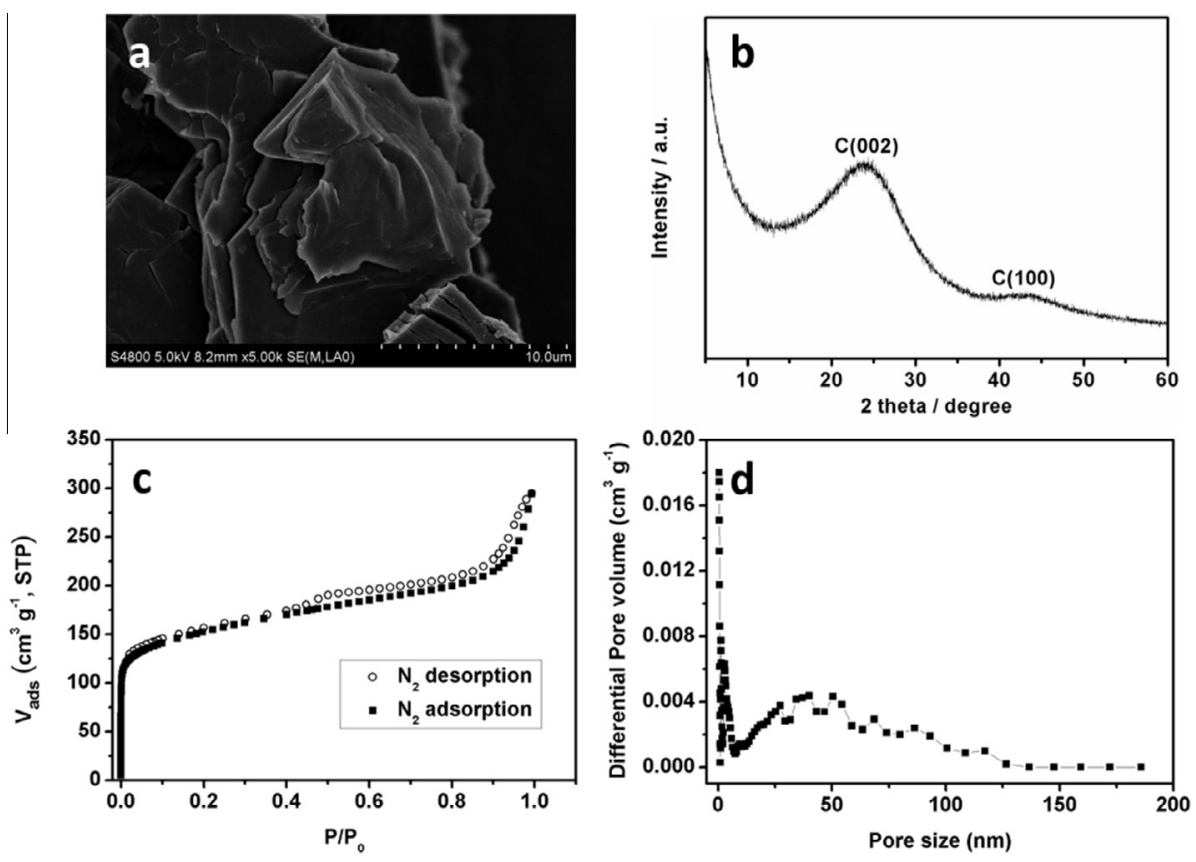

Fig. 2 - SEM image (a), XRD pattern (b), $\mathrm{N}_{2}$ sorption isotherms (c) and pore size distribution (d) of NPC800 (STP = standard temperature and pressure).

micropores in carbon. The gradual increase of curve at medium relative pressure with an evident hysteresis loop $\left(0.4<P / P_{0}<1\right)$ indicated the existence of mesopores [12]. In addition, the condensation effect occurred at high pressure revealed the probable existence of macropores. From the pore size distribution of NPC800 (Fig. 2d) obtained from density functional theory (DFT), it was seen that pores in the carbon were truly composed of large quantities of micropores, some mesopores and macropores, in accordance with $\mathrm{N}_{2}$ sorption isotherms in Fig. 2c. The existence of mesopores and micropores could result from the elimination of $\mathrm{Zn}$ elements and gasification of small molecules (e.g., $\mathrm{CO}_{2}, \mathrm{H}_{2} \mathrm{O}$ ) from compound 1 precursor. According to $\mathrm{N}_{2}$ adsorption data, the Brunauer-Emmett-Teller (BET) specific surface area and pore volume of NPC800 were calculated to be $562 \mathrm{~m}^{2} \mathrm{~g}^{-1}$ and $0.456 \mathrm{~cm}^{3} \mathrm{~g}^{-1}$, respectively, while the surface area of compound 1 was only $17 \mathrm{~m}^{2} \mathrm{~g}^{-1}$ calculated from Fig. S5 (Supporting information). Since ORR in fuel cell is an electrochemical reaction that takes place at the triple-phase boundary of reactants, catalyst, and electrolyte, high specific surface area and porosity of NPC800 help expose the catalytic site to reactant with enhanced mass-transport properties [39,40].

Besides surface property, the constitutions of NPC800 should be investigated in view of their great importance to the catalytic activity [39]. The mass ratio of $\mathrm{C}$ element to $\mathrm{N}$ element was estimated to 5.2, indicating 2,2'-bipyridine moieties in compound 1 precursor served as nitrogen resource of NPC800. From XPS of NPC800 (Fig. S6, Supporting Information), it could be seen that $\mathrm{Zn} 2 \mathrm{p} 3$ peaks coexisted with C1s, $\mathrm{N} 1 \mathrm{~s}$ and $01 \mathrm{~s}$ peaks. Only 0.67 at\% Zn was left, suggesting Zn was almost completely eliminated from porous carbon by carbonization and washing. The peaks at 284.6, 285.2, 285.8, 288.1 and $289.3 \mathrm{eV}$ in the C1s XPS spectrum (as shown in Fig. 3A) corresponded to the $\mathrm{sp}^{2}$-hybrizied graphitic carbon, C-N,
$\mathrm{C}-\mathrm{O}, \mathrm{C}=\mathrm{O}$ and $\mathrm{O}-\mathrm{C}=\mathrm{O}$, respectively [41-43], which were in agreement with FT-IR spectrum of NPC800 (Fig. S7, Supporting information). The peaks at 398.3, 400.1 and $401.2 \mathrm{eV}$ in the N1s XPS spectrum (as shown in Fig. 3B) corresponded to pyridinic $\mathrm{N}$, pyrrolic $\mathrm{N}$ and graphitic $\mathrm{N}$, respectively [44,45]. Importantly, the pyridinic $\mathrm{N}$ can provide active sites which offer NPC800 with good catalytic activity [30].

\subsubsection{Electrocatalytic behavior of NPC800 for ORR}

CV and LSV were utilized to investigate the electrocatalytic activity of NPC800 towards ORR in $0.1 \mathrm{~mol} \mathrm{~L}^{-1} \mathrm{KOH}$ solution. In Fig. 4A, CV curve obtained at NPC800 didn't show any redox peaks in $\mathrm{N}_{2}$-saturated solution at a scan rate of $20 \mathrm{mV} \mathrm{s}^{-1}$, but exhibited an obvious oxygen reduction peak at about $-0.28 \mathrm{~V}$ us. SCE when solution was saturated with $\mathrm{O}_{2}$. It suggested the electrocatalytic activity of NPC800 for ORR. For comparison, three electrodes, including bare RDE, $10 \% \mathrm{Pt} / \mathrm{C}$-modified RDE and NPC800-modified RDE, were utilized to investigate their electrocatalytic activity for ORR. From Fig. 4B, it was observed that the ORR onset potential of NPC800 was $-0.14 \mathrm{~V}$ us. SCE, which was more positive than bare RDE and similar to Pt/C. Moreover, the catalytic current for ORR performed by NPC800-modified RDE was higher than Pt/C-modified RDE. The above results illustrated that NPC800 showed the excellent electrocatalytic activity toward ORR.

The reasons for the advantage of NPC800 in ORR could be considered from the two aspects, (i) the high BET surface area facilitates mass transfer for exposing much active sites to oxygen [21]; (ii) the pyridinic $\mathrm{N}$ atoms possess electronaccepting ability that creates net positive on adjacent carbon atoms in the porous carbons to be capable of attracting electrons from the anode, thus promoting ORR [46]. In other words, the remarkable electrocatalytic property of NPC800 

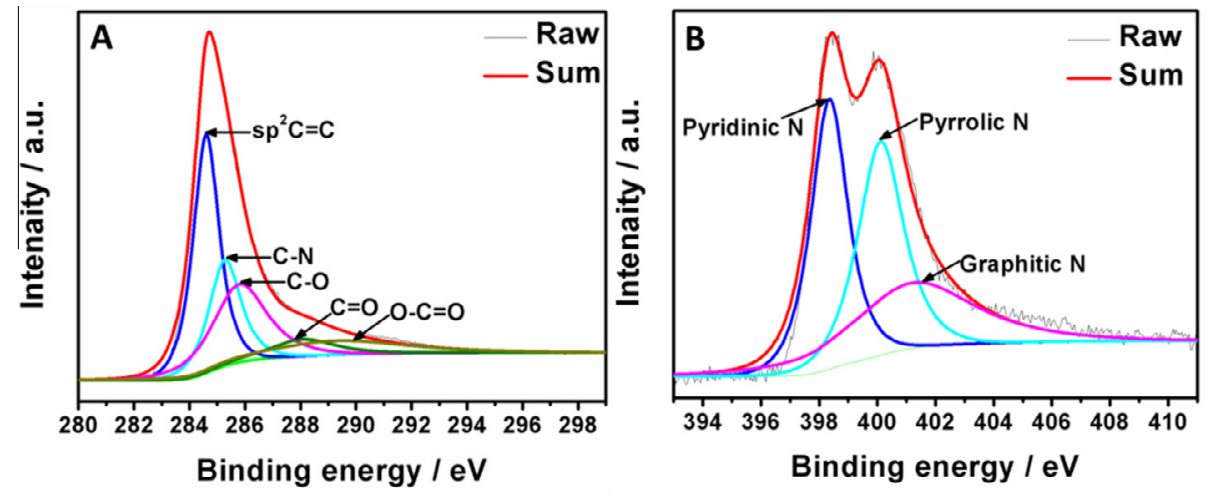

Fig. 3 - C1s (A) and N1s (B) XPS spectra of NPC800. (A color version of this figure can be viewed online.)
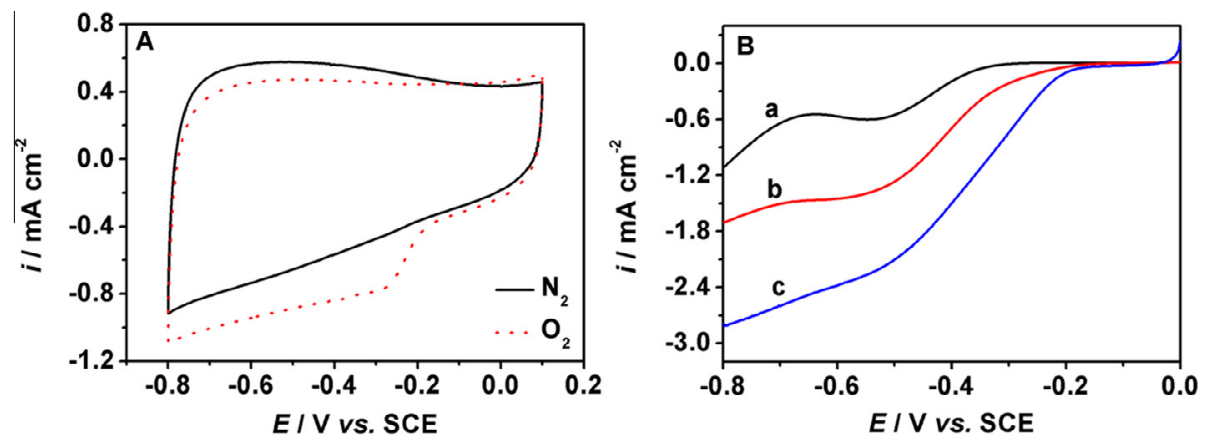

Fig. 4 - (A) CV curves of NPC800-modified GCE in $\mathrm{N}_{2}$ (solid curve) or $\mathrm{O}_{2}$ (dotted curve)-saturated $0.1 \mathrm{~mol} \mathrm{~L}^{-1} \mathrm{KOH}$ at a scan rate of $20 \mathrm{mV} \mathrm{s}^{-1}$; (B) LSVs of bare RDE (a), 10\% Pt/C-modified RDE (b) and NPC800-modified RDE (c) in $\mathrm{O}_{2}$-saturated $0.1 \mathrm{~mol} \mathrm{~L}^{-1} \mathrm{KOH}$ at a scan rate of $2 \mathrm{mV} \mathrm{s}^{-1}$. Rotation speed is $1600 \mathrm{rpm}$. (A color version of this figure can be viewed online.)

resulted from the synergistic effect between high surface area of carbon and appropriate content of nitrogen.

In order to further analyze the electrocatalytic property of NPC800, RDE linear sweep voltammetry was performed at different rotation rates. As shown in Fig. 5A, the current increased with the rotation rate increasing from 400 to $2000 \mathrm{rpm}$. Koutecky-Levich plots at different electrode potentials were linear (Fig. 5B), suggesting that oxygen reduction reaction followed the typical first-order reaction kinetics for dissolved oxygen [47]. Furthermore, the electron transfer numbers were calculated according to Koutecky-Levich equation [48]:
$\frac{1}{i}=\frac{1}{i_{k}}+\frac{1}{B \omega^{1 / 2}}$

$B=0.2 n F A C_{0}\left(D_{0}\right)^{2 / 3} v^{-1 / 6}$

in which $i$ was the measured current, $i_{k}$ was the kinetic current, $\omega$ was the rotation rate of electrode (rpm), $n$ was electron transfer numbers per oxygen molecular, $F$ was the Faradaic constant $\left(96485 \mathrm{C} \mathrm{mol}^{-1}\right), \quad A$ was the electrode area $\left(0.08 \mathrm{~cm}^{2}\right), C_{0}$ was the oxygen concentration in $0.1 \mathrm{~mol} \mathrm{~L}^{-1}$ $\mathrm{KOH}\left(1.2 \times 10^{-6} \mathrm{~mol} \mathrm{~cm}^{-3}\right), D_{0}$ was the oxygen diffusion coefficient in $0.1 \mathrm{~mol} \mathrm{~L}^{-1} \mathrm{KOH}\left(1.73 \times 10^{-5} \mathrm{~cm}^{2} \mathrm{~s}^{-1}\right)$ and $v$ was the
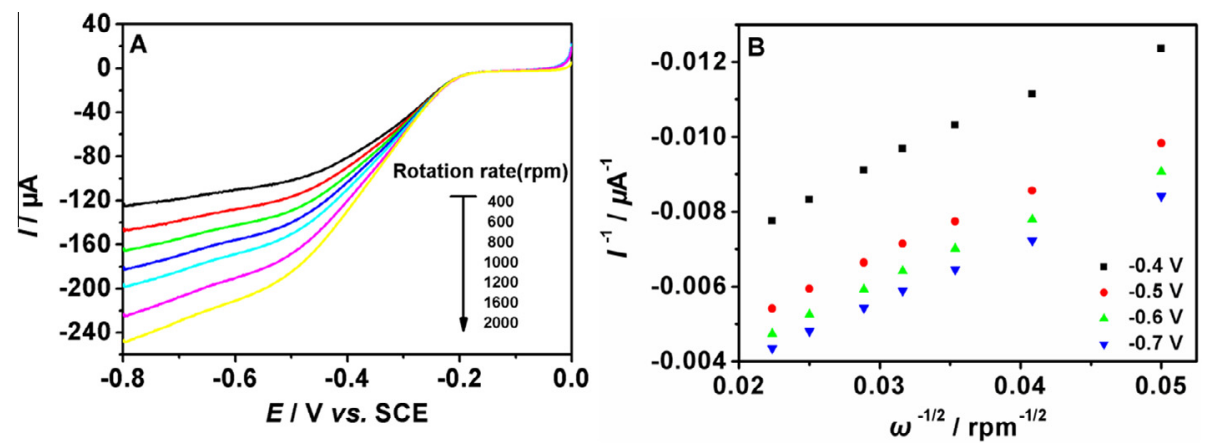

Fig. 5 - (A) RDE linear sweep voltammograms of NPC800-modified RDE in $\mathrm{O}_{2}$-saturated 0.1 mol $\mathrm{L}^{-1} \mathrm{KOH}$ with various rotation rates at a scan rate of $2 \mathrm{mV} \mathrm{s}^{-1}$; (B) Koutecky-Levich plots of NPC800-modified RDE at different electrode potentials. (A color version of this figure can be viewed online.) 

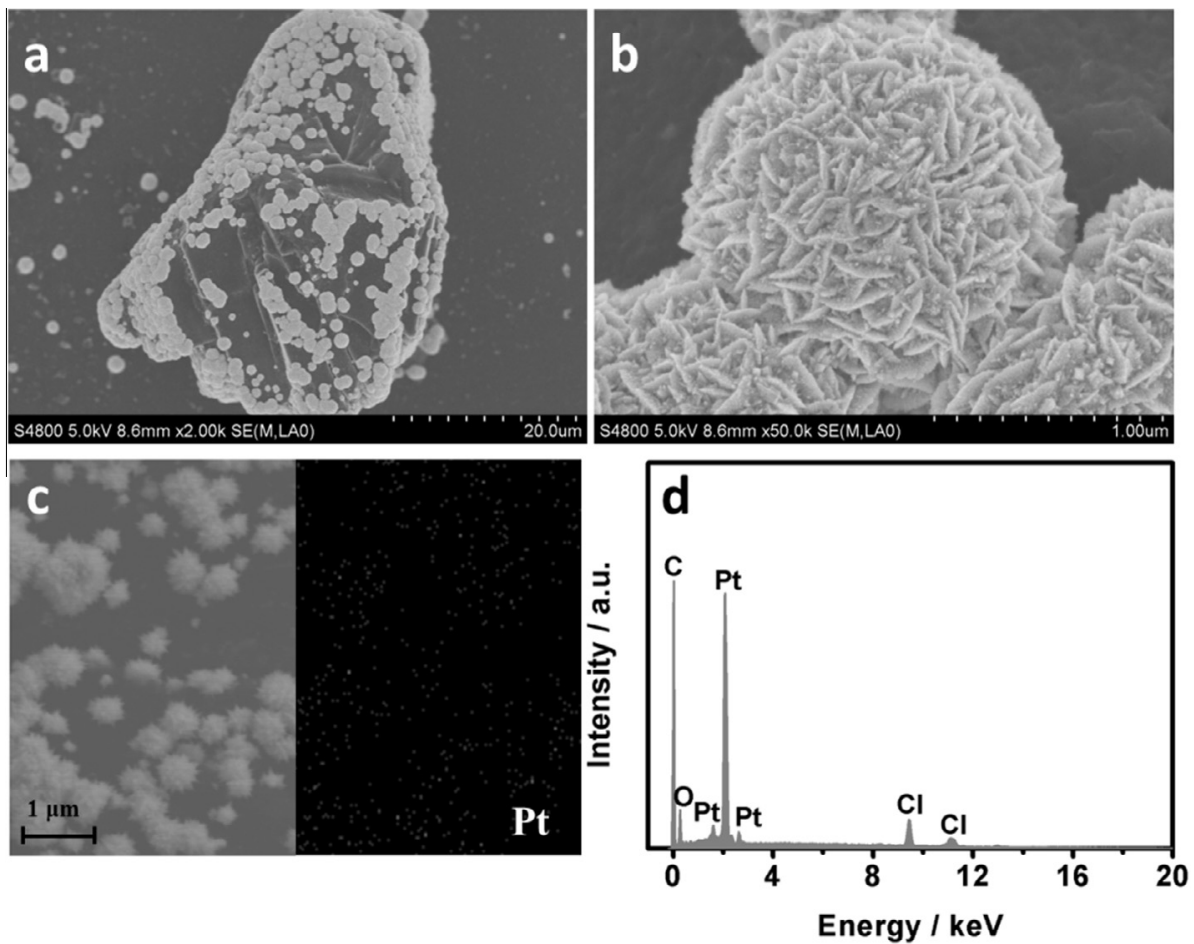

Fig. 6 - SEM images of Pt/NPC800 at different magnifications ( $a$ and b); Elemental mapping image of Pt for metal nanoparticle of Pt/NPC800 (c); EDS of Pt/NPC800 (d).

kinematic viscosity of the $0.1 \mathrm{~mol} \mathrm{~L}^{-1} \mathrm{KOH}\left(0.01 \mathrm{~cm}^{2} \mathrm{~s}^{-1}\right)$ $[49,50]$. The oxygen can be reduced to $\mathrm{H}_{2} \mathrm{O}_{2}$ through 2-electron transfer pathway or $\mathrm{H}_{2} \mathrm{O}$ through 4-electron transfer pathway [51]. In this work, $n$ was derived to 2.2-2.6 at different electrode potentials, indicating oxygen reduction preceded mainly through 2-electron transfer pathway and less by 4electron transfer pathway. It is noteworthy that the nitrogen atoms in this carbon can polarize the adjacent carbon atom because of their electron-accepting ability and create a radical carbon site to stabilize $\mathrm{OOH}$ with bonding affinity [51,52]. This condition may be responsible for the formation of $\mathrm{H}_{2} \mathrm{O}_{2}$. Despite the fact that NPC800 catalyzed oxygen reduction mainly by 2-electron pathway other than 4-electron, its excellent electroactivity enables it to serve as electrocatalyst for ORR.

\subsection{NPC800 for Pt-catalyst support}

\subsubsection{Deposition of Pt on NPC800}

In order to prepare Pt/NPC800 for MOR, Pt particles were deposited on NPC800 through electrodeposition (amperometric $i-t$ curve). We can control the loading amount of Pt by controlling the electrodeposition time. The amount of $\mathrm{Pt}$ deposited on NPC800 in this study was determined to $2.72 \mu \mathrm{g}$ (Pt-loading amount was $21 \mathrm{wt} \%$ ) according to amperometric i-t curve (Inset of Fig. S8, Supporting information), supposing that $\mathrm{Pt}^{4+}$ was reduced to $\mathrm{Pt}^{0}$ with $100 \%$ efficiency [53]. By means of typical adsorption and desorption peaks of hydrogen between -0.2 and $0.1 \mathrm{~V}$ in Fig. S8 (Supporting information), the electrochemically active surface area (ECSA) of catalyst can be estimated. Taking advantage of ECSA, some important information can be acquired, including the number of catalytic active sites available for an electrochemical reaction and the conductive pathway available to transfer electrons to and from the electrode surface [32]. The ECSA can be determined according to the following calculation formula [54]:

$\mathrm{ECSA}=\mathrm{Q}_{\mathrm{H}} / m \times q_{\mathrm{H}}$

$\mathrm{Q}_{\mathrm{H}}=\int \mathrm{IdE} / \mathrm{v}$

in which $m$ was the loading amount of metal, $q_{H}$ was a conversion factor for adsorption of a monolayer of hydrogen on Pt surface $\left(0.21 \mathrm{mC} \mathrm{cm}^{-2}\right), v$ was the scan rate and $\mathrm{Q}_{\mathrm{H}}$ was the charge for hydrogen adsorption which can be obtained from the area under the CV curve. In this paper, the ECSA of NPC800 was determined to $26.7 \mathrm{~m}^{2} \mathrm{~g}^{-1}$, which was comparable to the commercial $20 \% \mathrm{Pt} / \mathrm{C}$ [55]. Such a ECSA provided the NPC800 electrochemical accessibility.

\subsubsection{Physical characterization of Pt/NPC800}

Fig. $6 a$ and $b$ showed the SEM images of Pt/NPC800 at different magnifications. It was observable that Pt slice-like aggregates [56] had successfully loaded on NPC800 through electrodeposition and the average size of Pt particles was about $1 \mu \mathrm{m}$. It was worthy of noting that Pt particles mainly deposited on NPC800 other than glassy carbon electrode substrate, which was possibly due to the stabilization of Pt particles by NPCs. It suggested that NPC800 could serve as the support of noble metal effectively. In addition, the elemental mapping image of metal nanoparticle showed a good dispersion of Pt nanoparticles (Fig. 6c). The elemental composition of Pt/NPC800 on GCE was investigated by EDS (as shown in Fig. 6d). One 
can see that the major elements in Pt/NPC800 were C and Pt, which confirmed the coverage of NPC800 support by Pt. The existence of element $\mathrm{Cl}$ may be from $\mathrm{H}_{2} \mathrm{PtCl}_{6}$ or $\mathrm{HCl}$ during electrodeposition. The absence of $\mathrm{N}$ element in Fig. $6 \mathrm{~d}$ could be caused by the large coverage of Pt particles on NPC800 surface. In XRD pattern of Pt/NPC800 (Fig. S9, Supporting Information), the diffraction peaks at $2 \theta$ about $40^{\circ}, 47^{\circ}, 67^{\circ}$ and $80^{\circ}$ were ascribed to $\mathrm{Pt}(111), \mathrm{Pt}(200), \mathrm{Pt}(220)$ and $\mathrm{Pt}(311)$ crystalline planes, indicating the face-centered cubic (fcc) of Pt crystals. The other peaks were assigned to the nature diffraction of glassy carbon substrate.

\subsubsection{Electrocatalytic behavior of Pt/NPC800 for MOR}

The electrocatalytic activity of Pt/NPC800 toward methanol oxidation was investigated in $\mathrm{N}_{2}$-saturated $0.5 \mathrm{~mol} \mathrm{~L}^{-1}$ $\mathrm{H}_{2} \mathrm{SO}_{4}$ and $0.5 \mathrm{~mol} \mathrm{~L}^{-1}$ methanol solution between -0.1 and 1.0 V. Curve a in Fig. 7 presented two typical oxidation peaks of Pt/NPC800 in methanol oxidation, while methanol oxidation could scarcely be seen for bare GCE (curve $b$ in the inset of Fig. 7) and NPC800-modified GCE (curve $c$ in the inset of Fig. 7). The forward anodic peak $\left(I_{\mathrm{f}}\right)$ at about $0.67 \mathrm{~V}$ vs. Ag/AgCl was assigned to the oxidation of methanol, while the anodic peak $\left(I_{b}\right)$ at about $0.48 \mathrm{~V}$ vs. $\mathrm{Ag} / \mathrm{AgCl}$ in the backward scan was ascribed to the oxidation of carbonaceous species formed during the oxidation of methanol. $I_{\mathrm{f}} / \mathrm{I}_{\mathrm{b}}$ was an important parameter to evaluate the tolerance of catalyst to poisoning species, $\mathrm{Pt}=\mathrm{C}=\mathrm{O}$ [57]. The higher $\mathrm{I}_{\mathrm{f}} / \mathrm{I}_{\mathrm{b}}$ ratio means that the poisoning species can be removed from the catalysts more effectively [58]. The value of $I_{f} / I_{b}$ in this study was 0.90 , which was a median value in the reported literatures [55,57]. Chronoamperometric curve as another important element to assess the catalyst in methanol oxidation [32] were performed to further investigate the stability of Pt/NPC800. The stability of methanol oxidation on Pt/NPC800 was compared with that on Pt/XC-72 with the same Pt-loading amount in Fig. 8. It was clearly to see the current density obtained at Pt/NPC800 and

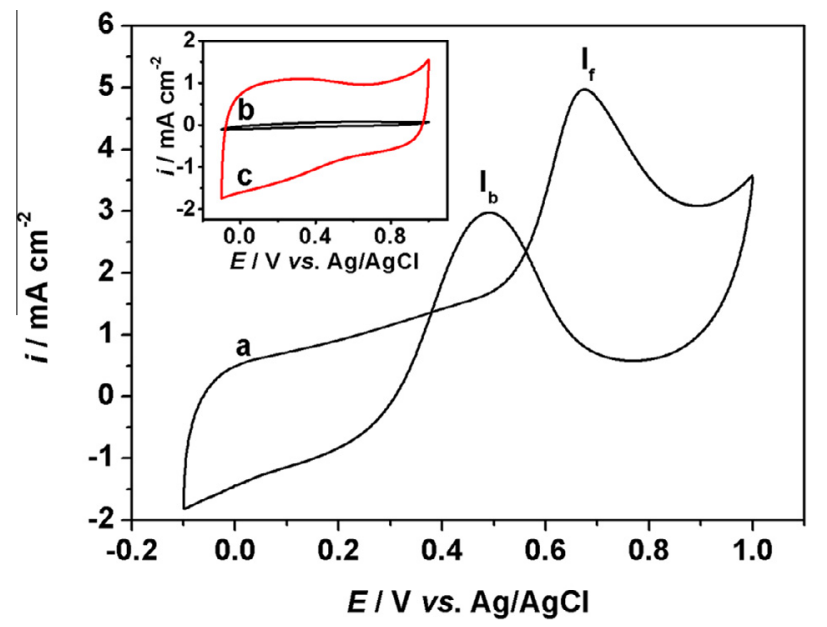

Fig. 7 - CV curve of methanol oxidation on Pt/NPC800 GCE (a) in $\mathrm{N}_{2}$-saturated $0.5 \mathrm{~mol} \mathrm{~L}^{-1} \mathrm{H}_{2} \mathrm{SO}_{4}$ and $0.5 \mathrm{~mol} \mathrm{~L}^{-1}$ methanol solution at a scan rate of $50 \mathrm{mV} \mathrm{s}^{-1}$. Insets are $\mathrm{CV}$ curves of bare GCE (b) and NPC800-modified GCE (c) in above solution at a scan rate of $50 \mathrm{mV} \mathrm{s}^{-1}$. (A color version of this figure can be viewed online.)

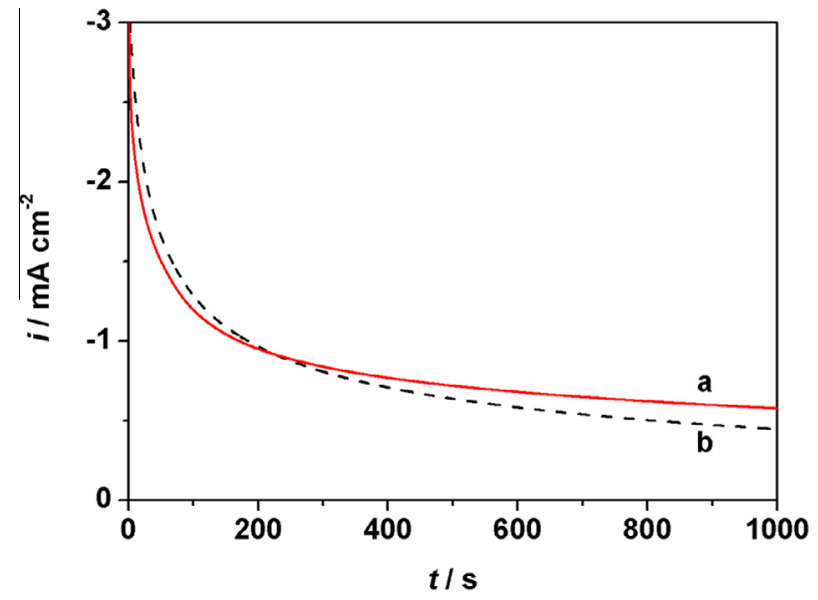

Fig. 8 - Chronoamperometric curves on Pt/NPC800 GCE (a) and Pt/XC-72 GCE (b) in $\mathrm{N}_{2}$-saturated $0.5 \mathrm{~mol} \mathrm{~L}^{-1} \mathrm{H}_{2} \mathrm{SO}_{4}$ and $0.5 \mathrm{~mol} \mathrm{~L}^{-1}$ methanol solution. (A color version of this figure can be viewed online.)

Pt/XC-72 decreased rapidly at the initial period and then reached an almost steady value. However, the decrease rate of current on Pt/NPC800 was lower than that on Pt/XC-72 and the final current value on Pt/NPC800 was higher than on Pt/XC-72. The better stability of Pt/NPC800 was due to the enhanced Pt-C bond strength between Pt particles and support, which could result from the changed $\pi$ bonding and increased basicity provided by the coexistence of $\mathrm{N}$ $[34,59,60]$. Combining the stability and the tolerance to poisoning species, Pt/NPC800 was regarded as a good catalyst for methanol electrooxidation.

\section{Conclusion}

A novel pyridine-containing MOF precursor has been designed and synthesized to prepare the nitrogen-doped porous carbon (NPC800) by direct carbonization. The as-prepared NPC800 was utilized as the electrocatalyst and catalyst support of ORR and MOR, respectively. The onset potential of NPC800 for ORR was $-0.14 \mathrm{~V}$ us. SCE, which was similar to commercial $\mathrm{Pt} / \mathrm{C}$. Notably, its catalytic current was higher than Pt/C. The remarkable activity of NPC800 toward ORR was probably due to the synergistic effect of the high BET surface area and the presence of nitrogen atoms in porous carbon. The Pt-catalyst supported on NPC800 possessed electrocatalytic activity for MOR and had better stability than Pt/XC-72 because of the enhanced bond strength between Pt and N-doped support. Such a strategy for using pyridine ligands as nitrogen source to prepare NPCs from MOFs precursor was very effective and be expected to generate highly efficient and stable catalyst for more electrochemical applications.

\section{Acknowledgements}

This work was financially supported by National Natural Science Foundation of China (Grant No. 21173246 and 21103215) and the "Hundred-talent Project" (KJCX2-YW-W34) of the Chinese Academy of Sciences. 


\section{Appendix A. Supplementary data}

Supplementary data associated with this article can be found, in the online version, at http://dx.doi.org/10.1016/j.carbon. 2014.08.013.

\section{R E F E R E N C E S}

[1] Zhao XB, Xiao B, Fletcher AJ, Thomas KM. Hydrogen adsorption on functionalized nanoporous activated carbons. J Phys Chem B 2005;109(18):8880-8.

[2] Xia Y, Yang Z, Zhu Y. Porous carbon-based materials for hydrogen storage: advancement and challenges. J Mater Chem A 2013;1(33):9365-81.

[3] Zhao Y, Liu X, Yao KX, Zhao L, Han Y. Superior capture of $\mathrm{CO}_{2}$ achieved by introducing extra-framework cations into $\mathrm{N}$ doped microporous carbon. Chem Mater 2012;24(24):4725-34.

[4] Hao GP, Jin ZY, Sun Q Zhang XQ, Zhang JT, Lu AH. Porous carbon nanosheets with precisely tunable thickness and selective $\mathrm{CO}_{2}$ adsorption properties. Energy Environ Sci 2013;6(12):3740-7.

[5] Wang Y, Jiang X. Facile preparation of porous carbon nanosheets without template and their excellent electrocatalytic property. ACS Appl Mater Interfaces 2013;5(22):11597-602.

[6] Balgis R, Sago S, Anilkumar GM, Ogi T, Okuyama K. Selforganized macroporous carbon structure derived from phenolic resin via spray pyrolysis for high-performance electrocatalyst. ACS Appl Mater Interfaces 2013;5(22):11944-50.

[7] Fang B, Bonakdarpour A, Kim MS, Kim JH, Wilkinson DP, Yu JS. Multimodal porous carbon as a highly efficient electrode material in an electric double layer capacitor. Micropor Mesopor Mater 2013;182:1-7.

[8] Zhou M, Pu F, Wang Z, Guan S. Nitrogen-doped porous carbons through $\mathrm{KOH}$ activation with superior performance in supercapacitors. Carbon 2014;68:185-94.

[9] Fuertes AB, Lota G, Centeno TA, Frackowiak E. Templated mesoporous carbons for supercapacitor application. Electrochim Acta 2005;50(14):2799-805.

[10] Zhang ZJ, Cui P, Chen C, Chen XY, Liu JW. Porous carbon synthesized by direct carbonization of potassium biphthalate for high-performance supercapacitors. J Solid State Electrochem 2014;18:59-67.

[11] Wang HL, Gao QM, Hu J. High hydrogen storage capacity of porous carbons prepared by using activated carbon. J Am Chem Soc 2009;131(20):7016-22.

[12] Liu B, Shioyama H, Akita T, Xu Q. Metal-organic framework as a template for porous carbon synthesis. J Am Chem Soc 2008;130(16):5390-1.

[13] Almasoudi A, Mokaya R. Preparation and hydrogen storage capacity of templated and activated carbons nanocast from commercially available zeolitic imidazolate framework. J Mater Chem 2012;22(1):146.

[14] Sevilla M, Fuertes AB. Sustainable porous carbons with a superior performance for $\mathrm{CO}_{2}$ capture. Energy Environ Sci 2011;4(5):1765.

[15] Sevilla M, Mokaya R, Fuertes AB. Ultrahigh surface area polypyrrole-based carbons with superior performance for hydrogen storage. Energy Environ Sci 2011;4(8):2930.

[16] Jiang HL, Liu B, Lan YQ, Kuratani K, Akita T, Shioyama H, et al. From metal-organic framework to nanoporous carbon: toward a very high surface area and hydrogen uptake. J Am Chem Soc 2011;133(31):11854-7.
[17] Ma SQ Goenaga GA, Call AV, Liu DJ. Cobalt imidazolate framework as precursor for oxygen reduction reaction electrocatalysts. Chem Eur J 2011;17(7):2063-7.

[18] Radhakrishnan L, Reboul J, Furukawa S, Srinivasu P, Kitagawa S, Yamauchi Y. Preparation of microporous carbon fibers through carbonization of Al-based porous coordination polymer (Al-PCP) with furfuryl alcohol. Chem Mater 2011;23(5):1225-31.

[19] Chaikittisilp W, Hu M, Wang H, Huang HS, Fujita T, Wu KC, et al. Nanoporous carbons through direct carbonization of a zeolitic imidazolate framework for supercapacitor electrodes. Chem Commun 2012;48(58):7259-61.

[20] Yang SJ, Kim T, Im JH, Kim YS, Lee K, Jung H, et al. MOFderived hierarchically porous carbon with exceptional porosity and hydrogen storage capacity. Chem Mater 2012;24(3):464-70.

[21] Zhao D, Shui JL, Chen C, Chen XQ, Reprogle BM, Wang DP, et al. Iron imidazolate framework as precursor for electrocatalysts in polymer electrolyte membrane fuel cells. Chem Sci 2012;3(11):3200-5.

[22] Wang Q, Xia W, Guo W, An L, Xia D, Zou R. Functional zeoliticimidazolate-framework-templated porous carbon materials for $\mathrm{CO}_{2}$ capture and enhanced capacitors. Chem Asian J 2013;8(8):1879-85.

[23] Xi K, Cao S, Peng XY, Ducati C, Kumar RV, Cheetham AK. Carbon with hierarchical pores from carbonized metalorganic frameworks for lithium sulphur batteries. Chem Commun 2013;49(22):2192-4.

[24] Amali AJ, Sun JK, Xu Q. From assembled metal-organic framework nanoparticles to hierarchically porous carbon for electrochemical energy storage. Chem Commun 2014;50(13):1519-22.

[25] Zhang P, Sun F, Xiang Z, Shen Z, Yun J, Cao D. ZIF-derived in situ nitrogen-doped porous carbons as efficient metal-free electrocatalysts for oxygen reduction reaction. Energy Environ Sci 2014;7(1):442-50.

[26] Hu JA, Wang HL, Gao QM, Guo HL. Porous carbons prepared by using metal-organic framework as the precursor for supercapacitors. Carbon 2010;48(12):3599-606.

[27] Liu B, Shioyama H, Jiang HL, Zhang XB, Xu Q. Metal-organic framework (MOF) as a template for syntheses of nanoporous carbons as electrode materials for supercapacitor. Carbon 2010;48(2):456-63.

[28] Lim S, Suh K, Kim Y, Yoon M, Park H, Dybtsev DN, et al. Porous carbon materials with a controllable surface area synthesized from metal-organic frameworks. Chem Commun 2012;48(60):7447-9.

[29] Aiyappa HB, Pachfule P, Banerjee R, Kurungot S. Porous carbons from nonporous MOFs: influence of ligand characteristics on intrinsic properties of end carbon. Cryst Growth Des 2013;13(10):4195-9.

[30] Chen Z, Higgins D, Chen ZW. Nitrogen doped carbon nanotubes and their impact on the oxygen reduction reaction in fuel cells. Carbon 2010;48(11):3057-65.

[31] Baena-Moncada AM, Planes GA, Moreno MS, Barbero CA. A novel method to produce a hierarchical porous carbon as a conductive support of PtRu particles. Effect on CO and methanol electrooxidation. J Power Sources 2013;221:42-8.

[32] Liang Q, Zhang L, Cai M, Li Y, Jiang K, Zhang X, et al. Preparation and charaterization of Pt/functionalized graphene and its electrocatalysis for methanol oxidation. Electrochim Acta 2013;111:275-83.

[33] Su F, Tian Z, Poh CK, Wang Z, Lim SH, Liu Z, et al. Pt nanoparticles supported on nitrogen-doped porous carbon nanospheres as an electrocatalyst for fuel cells. Chem Mater 2010;22(3):832-9.

[34] Shao YY, Sui JH, Yin GP, Gao YZ. Nitrogen-doped carbon nanostructures and their composites as catalytic materials 
for proton exchange membrane fuel cell. Appl Catal B Environ 2008;79(1-2):89-99.

[35] Li LJ, Tang SF, Lv XX, Cai JJ, Wang C, Zhao XB. A series of exceptionally robust luminescent coordination polymers based on a bipyridyldicarboxylate ligand and rare-earthmetal ions. Eur J Inorg Chem 2013;2013(36):6111-8.

[36] Li L, Tang S, Wang C, Lv X, Jiang M, Wu H, et al. High gas storage capacities and stepwise adsorption in a UiO type metal-organic framework incorporating lewis basic bipyridyl sites. Chem Commun 2014;50(18):2304-7.

[37] Huh S, Jung S, Kim Y, Kim SJ, Park S. Two-dimensional metalorganic frameworks with blue luminescence. Dalton Trans 2010;39(5):1261-5.

[38] Cai J, Li L, Lv X, Yang C, Zhao X. Large surface area ordered porous carbons via nanocasting zeolite $10 \mathrm{X}$ and high performance for hydrogen storage application. ACS Appl Mater Interfaces 2014;6(1):167-75.

[39] Jaouen F, Herranz J, Lefevre M, Dodelet JP, Kramm UI, Herrmann I, et al. Cross-laboratory experimental study of non-noble-metal electrocatalysts for the oxygen reduction reaction. ACS Appl Mater Interfaces 2009;1(8):1623-39.

[40] Yan Z, Zhang M, Xie J, Wang H, Wei W. Smaller Pt particles supported on mesoporous bowl-like carbon for highly efficient and stable methanol oxidation and oxygen reduction reaction. J Power Sources 2013;243:48-53.

[41] Chen P, Yang JJ, Li SS, Wang Z, Xiao TY, Qian YH, et al. Hydrothermal synthesis of macroscopic nitrogen-doped graphene hydrogels for ultrafast supercapacitor. Nano Energy 2013;2(2):249-56.

[42] Chen P, Xiao TY, Qian YH, Li SS, Yu SH. A nitrogen-doped graphene/carbon nanotube nanocomposite with synergistically enhanced electrochemical activity. Adv Mater 2013;25(23):3192-6.

[43] Li Y, Zhao Y, Cheng HH, Hu Y, Shi GQ Dai LM, et al. Nitrogendoped graphene quantum dots with oxygen-rich functional groups. J Am Chem Soc 2012;134(1):15-8.

[44] Kundu S, Nagaiah TC, Xia W, Wang Y, Van Dommele S, Bitter $\mathrm{JH}$, et al. Electrocatalytic activity and stability of nitrogencontaining carbon nanotubes in the oxygen reduction reaction. J Phys Chem C 2009;113(32):14302-10.

[45] Arrigo R, Havecker M, Schlogl R, Su DS. Dynamic surface rearrangement and thermal stability of nitrogen functional groups on carbon nanotubes. Chem Commun 2008;40:4891-3.

[46] Yu DS, Zhang Q Dai LM. Highly efficient metal-free growth of nitrogen-doped single-walled carbon nanotubes on plasmaetched substrates for oxygen reduction. J Am Chem Soc 2010;132(43):15127-9.

[47] Pourazadi E, Haque E, Zhang W, Harris AT, Minett AI. Synergistically enhanced electrochemical (ORR) activity of graphene oxide using boronic acid as an interlayer spacer. Chem Commun 2013;49(94):11068-70.

[48] Chen J, Zhang WM, Officer D, Swiegers GF, Wallace GG. A readily-prepared, convergent, oxygen reduction electrocatalyst. Chem Commun 2007;32:3353-5.

[49] Tham MK, Walker RD, Gubbins KE. Diffusion of oxygen and hydrogen in aqueous potassium hydroxide solutions. J Phys Chem 1970;74(8):1747-51.

[50] Davis RE, Horvath GL, Tobias CW. Solubility and diffusion coefficient of oxygen in potassium hydroxide solutions. Electrochim Acta 1967;12(3):287-97.

[51] Jahan M, Bao QL, Loh KP. Electrocatalytically active grapheneporphyrin MOF composite for oxygen reduction reaction. J Am Chem Soc 2012;134(15):6707-13.

[52] Sidik RA, Anderson AB, Subramanian NP, Kumaraguru SP, Popov BN. $\mathrm{O}_{2}$ reduction on graphite and nitrogen-doped graphite: experiment and theory. J Phys Chem B 2006;110(4):1787-93.

[53] Ficicioglu F, Kadirgan F. Electrooxidation of methanol on platinum doped polyaniline electrodes: deposition potential and temperature effect. J Electroanal Chem 1997;430(12):179-82.

[54] Wang YX, Zhou HJ, Sun PC, Chen TH. Exceptional methanol electro-oxidation activity by bimetallic concave and dendritic Pt-Cu nanocrystals catalysts. J Power Sources 2014;245:663-70.

[55] Zhang J, Guo S, Wei J, Xu Q, Yan W, Fu J, et al. High-efficiency encapsulation of Pt nanoparticles into the channel of carbon nanotubes as an enhanced electrocatalyst for methanol oxidation. Chem Eur J 2013;19(47):16087-92.

[56] Jiang M, Zhu D, Zhao X. Electrolysis of ammonia for hydrogen production catalyzed by Pt and Pt-Ir deposited on nickel foam. J Energy Chem 2014;23(1):1-8.

[57] Mu YY, Liang HP, Hu JS, Jiang L, Wan LJ. Controllable Pt nanoparticle deposition on carbon nanotubes as an anode catalyst for direct methanol fuel cells. J Phys Chem B 2005;109(47):22212-6.

[58] Guo SJ, Dong SJ, Wang EK. Polyaniline/Pt hybrid nanofibers: high-efficiency nanoelectrocatalysts for electrochemical devices. Small 2009;5(16):1869-76.

[59] Groves MN, Chan ASW, Malardier-Jugroot C, Jugroot M. Improving platinum catalyst binding energy to graphene through nitrogen doping. Chem Phys Lett 2009;481(46):214-9.

[60] Corpuz AR, Olson TS, Joghee P, Pylypenko S, Dameron AA, Dinh HN, et al. Effect of a nitrogen-doped PtRu/carbon anode catalyst on the durability of a direct methanol fuel cell. J Power Sources 2012;217:142-51. 